graphy giving details of previous studies in this and other related fields.

\section{Fishing Gear of England and Wales}

The Ministry of Agriculture, Fisheries and Food has recently published a revised edition of the late F. M. Davis's "An Account of the Fishing Gear of England and Wales" (Fishery Investigations, Series 2, Vol. 21, No. 8. Pp. v+165. London : H.M. Stationery Office, 1958. 35s. net). Although a new edition of this standard reference work, now twenty-two years old, is to be welcomed, one can only regret that the opportunity has not been taken to bring it thoroughly up to date. Far too much of the book is taken up with descriptions of methods which are of interest only to the historian of fishing - methods which could equally well be found in a library copy of the earlier editions. This leads to an imbalance in the presenta. tion. Thus the description of the Larsen trawl occupies no more space than that of the older (and much simpler) stownet which it has now almost entirely superseded, while the largely derelict fishing weirs, now only a memory to most fishing communities, receive fuller treatment than either. Despite, however, the resulting distortion of the overall picture of British fishing methods, the work remains an invaluable compendium of fishing practice around the United Kingdom.

\section{The Wonderboom}

Tee famous wonderboom tree of Pretoria has been described as "the most remarkable example of its species in Africa and a National Monument". This magnificent 'tree' nestles against the sheltered north slope of the Magaliesberg range, a few miles north of Pretoria and close to the River Apies. The tree is an evergreen wild fig, Ficus pretoriae Burtt-Davy. There are many examples of this species in the district, especially along the northern base of the Magaliesberg range, and fine specimens have been recorded as far west as Marico. The best-known individual tree is the klein wonderboom, which is to be found a quarter of a mile to the west of Wonderboom Poort. The wonderboom is remarkable because of its mode of spread; no other example of this species has been found which has attained such considerable dimensions. The spread resembles that of the strawberry plant, the branches taking root with new trunks growing up until the single tree looks like a miniature forest. In the klein wonderboom thirteen 'individuals' have arisen from the original trunk. From north-north-east to southsouth-west the diameter of the tree is about $170 \mathrm{ft}$. and from east to west about $145 \mathrm{ft}$. It is at least $74 \mathrm{ft}$. high. This famous banyan tree is described in a special issue of the Transvaal Fauna and Flora (No. 7; 1956), which is devoted entirely to the Wonderboom Nature Reserve.

\section{Respiration of Excised Tomato Roots}

IN a further contribution to our knowledge of the carbohydrate nutrition of tomato roots grown in pure culture, D. R. Morgan and H. E. Street have examined the sugars, and sugar phosphates and alcohols, which may serve as respiratory substrates ( $A n n$. Bot., N.S., $23,89 ; 1959)$. The respiratory responses of substrate-depleted excised root tips to a range of sugars, sugar phosphates and sugar alcohols were determined by measuring oxygen uptake by the direct method of Warburg. Sucrose, dextrose and Iævulose are the only sugars which promote a high level of oxygen uptake. The effects of azide and dinitrophenyl on the oxygen uptake promoted by sucrose and by dextrose are described. Mannose is a strong inhibitor of respiration. The inhibition is reversed by the simultaneous addition of those sugars which also reverse the growth inhibition caused by mannose. Mannose inhibits the respiration of sucrose and of glycolytic intermediates. Galactose is slowly respired and does not, even at high concentration, inhibit the respiration of sucrose.

\section{Standards of Radioactivity}

The U.S. National Bureau of Standards Circular No. 594, entitled "Preparation, Maintenance, and Application of Standards of Radioactivity", by W. B. Mann and H. H. Seliger (pp. iv +47. Washington, D.C. : Government Printing Office, 1958. 35 cents), is a revision and unification of two review articles originally published in 1956 (Internat. $J$. ATp. Rad. and Isotopes, 1,3 and $215 ; 1956)$. It sul'veys the current position in the field of standard. ization of radioactivity and describes the methods available for the preparation of both primary and secondary standards. The applications of the standards to problems in physics are discussed including historical and geological dating from halflives. One section is devoted to a summary of the results of the international comparisons of radioactivity standards which have been made during the past few years, and the circular concludes with an extensive bibliography. The main differences from the original articles are, apart from the inclusion of recent work, the use of a modified Harvard system of references and the incorporation of illustrations showing specifically the methods used at the National Bureau of Standards in the field of radioactivity.

\section{Radio Industry Council Premiums for Technical Writing}

The Radio Industry Council has announced the award of six premiums of 25 guineas each for papers on radio and electronics published during 1958, as follows : "A New High-efficiency High-power Amplifier", in The Marconi Review, by V. J. Tyler (Marconi's Wireless Telegraph Co., Ltd.); "Now Types of d.c. Amplifiers", Parts I and 2, in Electronic and Radio Engineer, by D. J. R. Martin (The Mining Research Establishment); "A Survey of Microwave Radio Communication", in Electronic Engineering, by W.J. Bray (Post Office Engineering Department); "All Travelling-wave Tube Systems", in Electronic Engineering, by S. Fedida (Marconi's Wireless Telegraph Co., Ltd.) ; "Electronic Developments at Very Low Temperatures", in British Communications and Electronics, by Dr. E. Mendoza (University of Manchester); "Analogue Computation", in British Communications and Electronics, by E. Lloyd Thomas (R. B. Pullin and Co., Ltd.).

\section{Institution of Electronics Premiums}

The Institution of Electronics is to award the following new premiums for papers accepted for publication in the Proceedings of the Institution of Electronics during 1959 : The Institution of Electronics Premium (25 gns.) for the most outstanding paper of the year ; the Electronic Applications Premium (20 gns.) for the most outstanding paper dealing with the practical application(s) of electronies; the New Electronic Device Premium (15 gns.) for the most outstanding paper dealing with a specific new electronic device; the Institution of Electronics Exhibi- 